\title{
Non-invasive diagnostic investigation at the Bishop's Palace of Frascati: an integrated approach
}

\author{
Luisa Caneve ${ }^{1}$, Francesco Colao ${ }^{1}$, Massimo Francucci ${ }^{1}$, Massimiliano Guarneri ${ }^{1}$, Marialuisa Mongelli ${ }^{2}$, \\ Valeria Spizzichino ${ }^{1}$
}

${ }^{1}$ ENEA - Diagnostic and Metrology Laboratory, Via Enrico Fermi 45, 00044 Frascati, Italy

2 ENEA - High Performance Computing Laboratory, Lungotevere Thaon di Revel 76, 00196 Rome, Italy

\begin{abstract}
Artistic surfaces at the Bishop's Palace of Frascati were investigated using an integrated approach involving different non-invasive diagnostic techniques. A novel remote methodology aimed at the detection and location of materials from previous restoration actions as well as the monitoring of degradation processes is proposed. In this novel approach, a laser-induced fluorescence (LIF) scanning system was used in synergy with a red-green-blue imaging topological radar 3D laser scanner and the structure from motion technique for 3D photogrammetric reconstruction. The spectral characteristics of the obtained LIF images permitted us to identify restoration materials and bio-deteriorated areas even when they were not visible to the naked eye. The superimposition of LIF and 3D images allowed for an optimised localisation of the areas of interest. The periodic repetition of this integrated approach could be used as a tool to monitor degradation processes as it could identify structural and chemical changes that occur in these areas of interest. The presented results could support the conservation, study and dissemination of cultural heritage items, keeping in mind that integration with information obtained through other innovative and standard analytical techniques is always fundamental.
\end{abstract}

\section{Section: RESEARCH PAPER}

Keywords: non-invasive techniques; LIF; 3D reconstruction; photogrammetry

Citation: Luisa Caneve, Francesco Colao, Massimo Francucci, Massimiliano Guarneri, Marialuisa Mongelli, Valeria Spizzichino, Non-invasive diagnostic investigation at the Bishop's Palace of Frascati: an integrated approach, Acta IMEKO, vol. 10, no. 1, article 24, March 2021, identifier: IMEKO-ACTA-10 (2021)01-24

Editor: Ioan Tudosa, University of Sannio, Italy

Received April 28, 2020; In final form November 12, 2020; Published March 2021

Copyright: This is an open-access article distributed under the terms of the Creative Commons Attribution 3.0 License, which permits unrestricted use, distribution, and reproduction in any medium, provided the original author and source are credited.

Funding: This work was supported by ADAMO project, funded by Lazio Region for Technological Cultural District (DTC-Lazio)

Corresponding author: Luisa Caneve, e-mail: luisa.caneve@enea.it

\section{INTRODUCTION}

In the frame of the project focusing on analysis, diagnosis and monitoring for cultural heritage conservation and restoration (ADAMO) financed by Lazio Region for the district of cultural technology (DTC Lazio), a measurement campaign was undertaken at the Bishop's Palace of Frascati, an ancient fortress that is now the home of the Episcopal Tuscolana Diocese. The measurements were performed to assess the status of previous restoration work. Following the requests of the Palace's caretaker, particular attention was devoted to the investigation of the so-called Stufetta Room the ground floor of the Palace (Figure 1), and the Landscape Room on the first floor, which offers a view of the garden.

An integrated investigation approach was adopted involving different non-invasive technologies and instruments. A laser- induced fluorescence (LIF) system developed at ENEA's Diagnostic and Metrology Laboratory and previously applied as a diagnostic tool in cultural heritage investigations was used. LIF is a suitable tool for the characterisation of valuable and unmovable targets due to its unique properties as a nondestructive, non-invasive remote technique using transportable or portable instruments that can provide first results in real time without sampling [1], [2]. LIF spectroscopy has already been successfully applied in archaeological sites, providing useful information to restorers [3], [3]. The validity of the technique as a diagnostic tool for artworks of different materials, such as paintings, ceramics, stonework and textiles, has also been demonstrated [4]-[7]. LIF-based systems are able to acquire fluorescence spectra and generate multispectral images that can be used to create a component material map of the investigated surface in order to identify and characterise materials of interest 


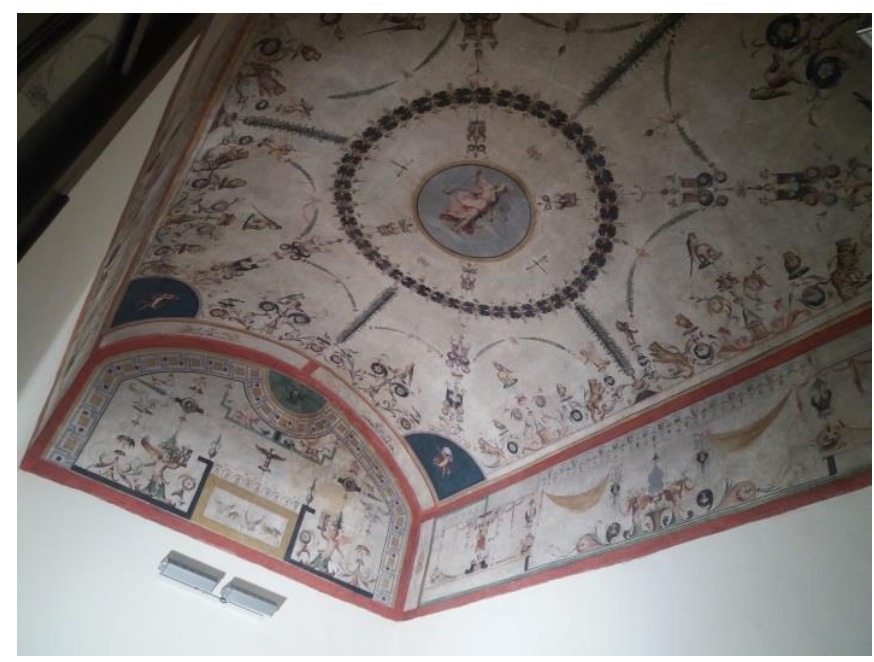

Figure 1. Stufetta vault at the Bishop's Palace of Frascati.

[9], [9]. In this study, this technology was used in synergy with other non-invasive techniques that can localise bio-deteriorated areas and added restoration materials in order to support and integrate the experimental results. In particular, the structure from motion (SfM) method [10] was used to obtain a 3D photogrammetric reconstruction of the painted vault of the Stufetta Room in a very short time with accurate structure in terms of geometry and texture. This technique is commonly applied in the study of cultural heritage assets [11]. Along with these instruments, a red-green-blue imaging topological radar (RGB-ITR) 3D laser scanner prototype was used to digitalise the Landscape Room. This 3D laser scanner has already been employed for remote diagnostics of cultural heritage [12], [14]. Its ability to measure in situ remotely along with its complete non-invasiveness eliminate the use of scaffolds, reducing the time and cost of the analysis. The obtained results highlighted the localised presence of different materials resulting from retouching or consolidating processes, even in areas where differences are not appreciable by the naked eye. Deterioration phenomena, mainly due to environmental humidity, were also localised by the system in places where they were not clearly evident, suggesting the possibility of early detection of damage. The available techniques for characterising and monitoring biodegradation [15], [15] can be supported by the presented approach.

The combined use of the different instruments offers several advantages. In particular, it is possible to overlay the LIF spectral maps onto the $3 \mathrm{D}$ photogrammetric model obtained at a shortto-medium range of distance and onto the 3D laser coloured model obtained by the RGB-ITR scanner. The system can also localise the areas on the surface that have submitted to degradation actions perfectly even in low light conditions or at great distances.

The results of the proposed integrated approach can be of great usefulness for site conservation. The ability to detect and localise early signs of damage before they are clearly visible using non-invasive and rapid techniques can ensure that interventions and restoration actions are performed in time. Moreover, the periodic repetition of this kind of investigation involving the combined results of different applied techniques regarding possible changes in the areas of interest, such as changes in the dimensions of bio-deteriorated areas or chemical degradation of the restoration materials, could be used to monitor degradation processes.

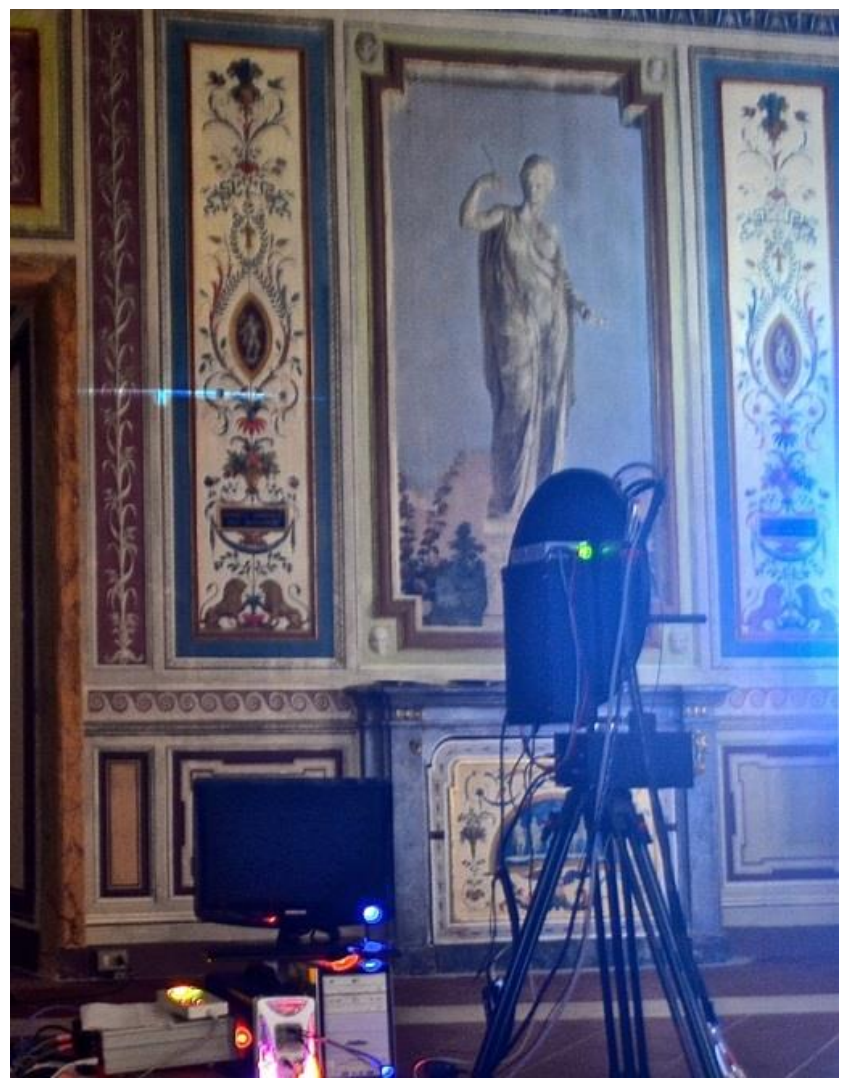

Figure 2. LIF system operating at the Bishop's Palace of Frascati. Laser beam line visible on the left wall.

\section{EXPERIMENTAL SETUP}

\subsection{Laser-induced fluorescence system}

The system applied in this work for fluorescence measurements was the ENEA prototype LIF line scanning system, in which a cylindrical lens in the optical path modifies the shape of the laser beam on the target from a point to a line. This system, shown in Figure 2 during the measurements at the Palace, is described in detail in a previously published paper [16]. The improvement of the optical system together with the new rotating mechanical assembly have made possible a considerable reduction of the scan time $\left(1.5 \times 5 \mathrm{~m}^{2}\right.$ scanned in less than 2 minutes at $25 \mathrm{~m}$ of distance from the target) in comparison to similar prototype systems developed previously [17], making this instrument particularly suitable for the analysis of large areas. Using motorised optics controlled by software, the laser beam, working in this case at the wavelength of $266 \mathrm{~nm}$, has a repetition rate of $20 \mathrm{~Hz}$, a pulse duration of $10 \mathrm{~ns}$ and $1.2 \mathrm{~mJ}$ of energy for carrying out surface scans. The ICCD camera has a $1024 \times 1024$ pixel detector. The LIF system's horizontal field of view is 6 degrees, and due to the coupling of optics and ICCD, only half of the available pixels are useful for collecting the fluorescence signal. As a consequence, the horizontal spatial resolution of the system is $1 \mathrm{~mm}$ when calculated at $5 \mathrm{~m}$ of distance from the target. A LabView program allows the user to set experimental parameters, define the scene to be scanned, control the different components of the system, acquire data and perform preliminary data processing quickly. Moreover, the vertical spatial resolution can be set by the software by defining the number of rows necessary for the scan in order to cover the whole selected area. 


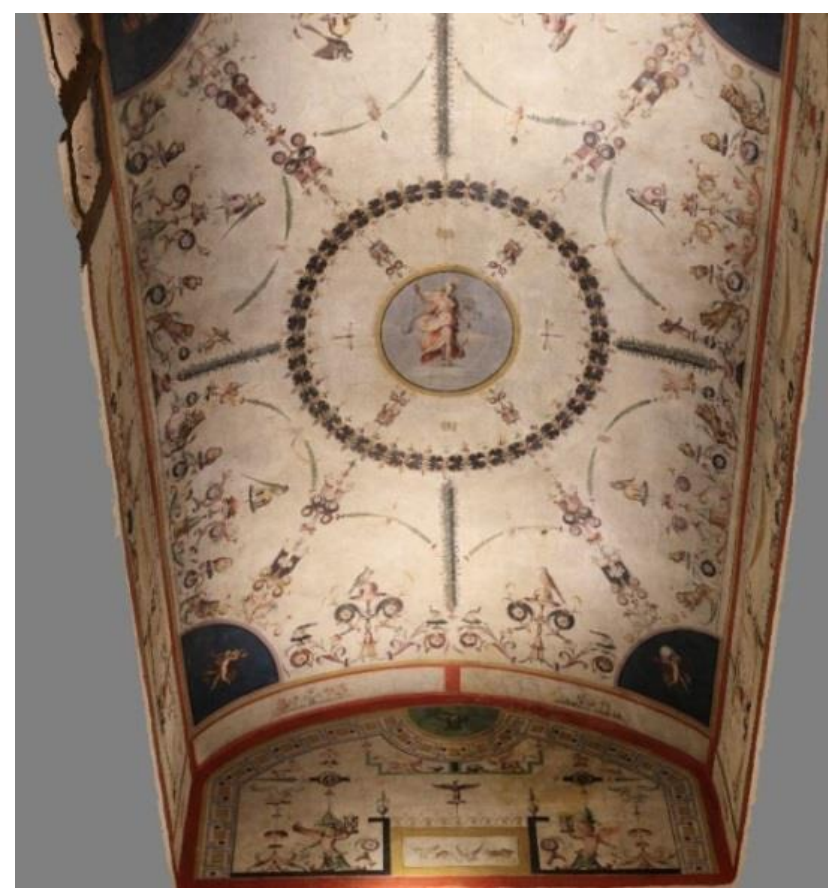

Figure 3. 3D photogrammetric reconstruction of the Stufetta tunnel vault.

The measurement time is affected by the value of this parameter, and it can change depending on the specific requirements.

The registration of all data related to both the system configuration and the acquisition parameters guarantees the measurement's repeatability once the placement of the instrument is fixed. Moreover, the LIF scanning system can be used with the laser switched off to collect reflectance images upon the availability of an intense standard light source that can be used as a spatial reference on the target surface. The whole fluorescence spectrum in the $270-900 \mathrm{~nm}$ range for every examined point with a spectral resolution of $2.5 \mathrm{~nm}$ and fluorescence images of the scanned surface are generated by the system. The fluorescence images can be elaborated and reconstructed in false colour by using the three most intense detected bands, corresponding to the main features, as red, green and blue channels (RGB), respectively.

\subsection{Photogrammetry}

Photogrammetry is a tested technique in the documentation of cultural heritage artefacts, and it has already been applied as a useful tool for cultural heritage surveys [18], [19].

$3 \mathrm{D}$ photogrammetric reconstruction using the SfM method is done to create three-dimensional models in a very fast and contactless way from the acquisition of two-dimensional digital images in the form of points cloud and/or polygonal mesh in order to fix their correct geometric data in terms of shape, size and spatial position. The SfM technique is based on the theoretical principles of optics, descriptive geometry fundamentals and, especially, inverse perspective theory: the scene reconstruction as well as the camera position and orientation are solved automatically by the software, using complex algorithms. One of the principal obstacles for the use of this technique is the large demands placed on hardware and software resources for image processing, data analysis and data storage, but the ability to access the computational resources offered by the ENEA computational infrastructure, especially the Computational Centre for Research on Complex Systems (CRESCO) high performance computing (HPC) infrastructure, allowed us to overcome this problem. The photogrammetric scan of the Stufetta tunnel vault is reported in Figure 3 and was carried out by a Canon EOS 550D reflex digital camera with a resolution of $18 \mathrm{MPixel}$, a focal length of $18 \mathrm{~mm}$ and a $22.3 \times 14.9$ $\mathrm{mm}$ CMOS sensor. The 115 2D 7.5 MB digital images were postprocessed remotely using the commercial code Photoscan Pro based on computer vision algorithms and SfM and multiple view stereovision (MVS) techniques. This was done via Internet, through IT@CHA virtual lab, which is completely dedicated to cultural heritage applications. IT@CHA was developed to enable users to access graphic codes, process digital images and produce $3 \mathrm{D}$ spatial data on the web using the hardware and software capabilities of the ENEA CRESCO HPC infrastructure, which is distributed over 6 geographical sites in Italy. In addition, the CRESCO system can process the large datasets required for many 3D reconstructions by providing computing facilities, storage resources and 3D data rendering tools [20].

Thanks to the use of the hardware and software resources of the ENEA computing infrastructure, it was possible to obtain the $3 \mathrm{D}$ reconstruction of the vault at scale in a very short time with an accurate structure in terms of geometry and texture.

\subsection{Red-green-blue imaging topological radar laser scanner}

The RGB-ITR, shown in Figure 4, is a light detection and ranging (LIDAR) scanner based on the amplitude modulation of laser beams and the use of the lock-in technique for estimations of both colour and structure information [21]. Two pieces of software designed for the system, ScanSystem and itrAnalyzer, allow the user to set the scan parameters, calibrate data, perform post-processing analyses and generate 3D models [22]. This instrument can be used at any time without being influenced by external factors such as the variability of the ambient light. Differently from other laser scanners, the RGB-ITR system positions the beam on the surface using a TV-like raster, which ensures the same resolution on the lateral walls and the top. The entire digitalisation was performed by placing the scanner in the middle of the room and rotating the optical head until the entire field of view was covered by the laser beams. In this particular case, the laser scanner was placed approximately $5 \mathrm{~m}$ away from the target; in general, it can operate from a distance of up to 35 $\mathrm{m}$. The resulting spot size of the 3 super-imposed laser beams was $0.3 \mathrm{~mm}$, while the spatial resolution was set at $0.5 \mathrm{~mm}$ as a good compromise between the scanning time and the image

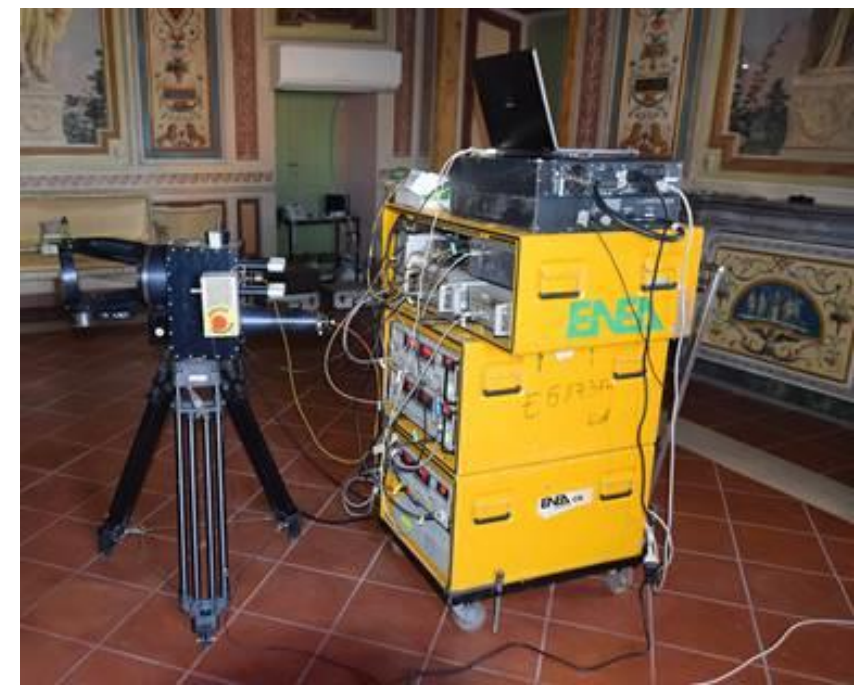

Figure 4. RGB-ITR laser scanner operating in the Landscape Room. 

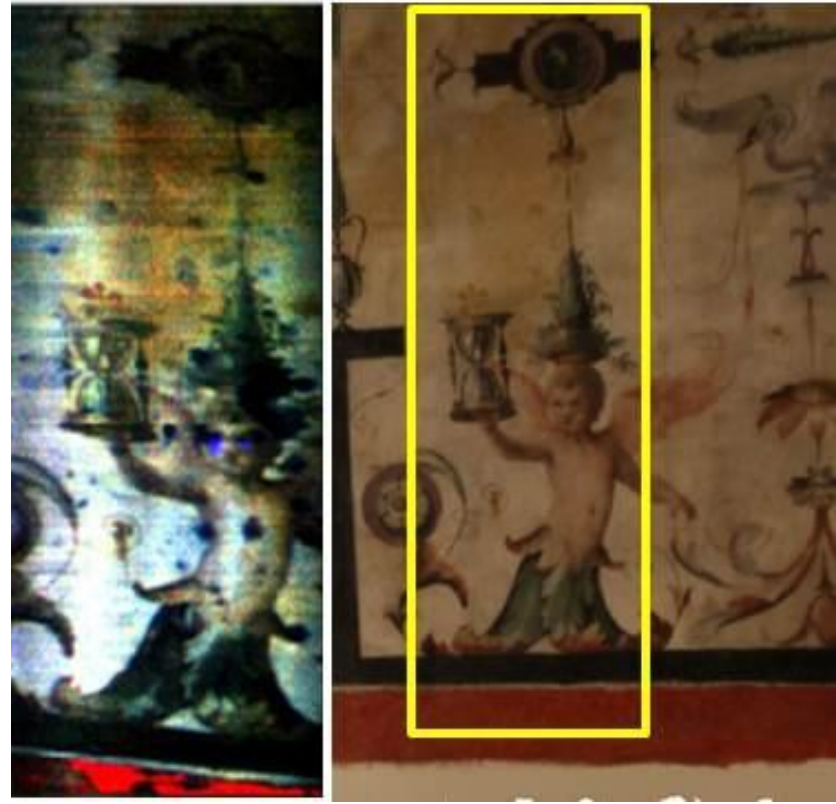

Figure 5. False colour LIF image reconstructed at 300, 400 and $500 \mathrm{~nm}$ on the left; photogrammetric image with measured area in the yellow line on the right.

resolution. The ITR scanner is based on a polar coordinate system, so its spatial resolution is dependent on the distance between the instrument and the target. In the presented case study, the acquisition was made at an average distance of $5 \mathrm{~m}$, and the angular point-to-point resolution of the motorised mirror was set at $2-4$ mdeg. The average point-to-point spatial resolution was about $0.3-0.5 \mathrm{~mm}$. A complete dissertation presenting a comparison of the image resolutions of standard commercial scanner cameras and RGB-ITR as well as comparisons of their data resolution and accuracy can be found in a published paper [23]. During the acquisition phase, a linear calibration procedure was completed that consisted of pointing

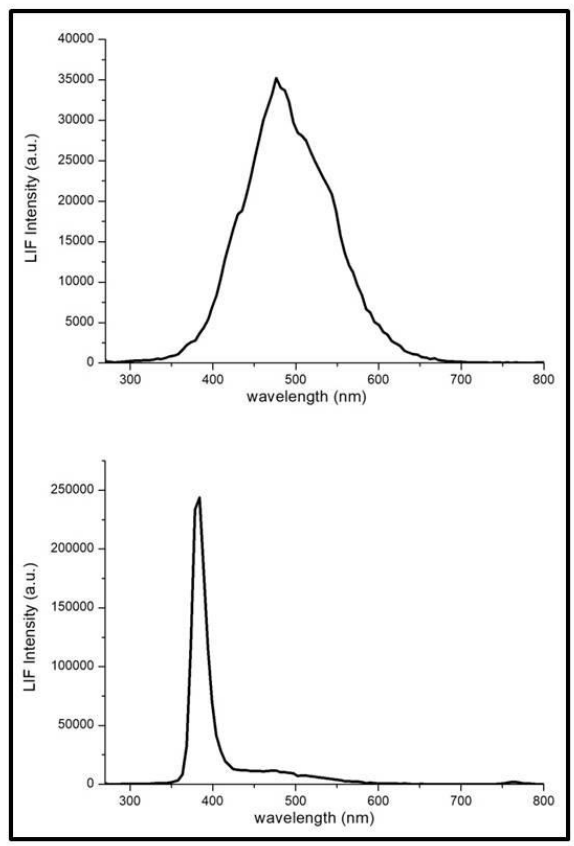

Figure 6. LIF spectra related to areas with evidence of biodeterioration (upper spectrum) and restoration materials (lower spectrum).

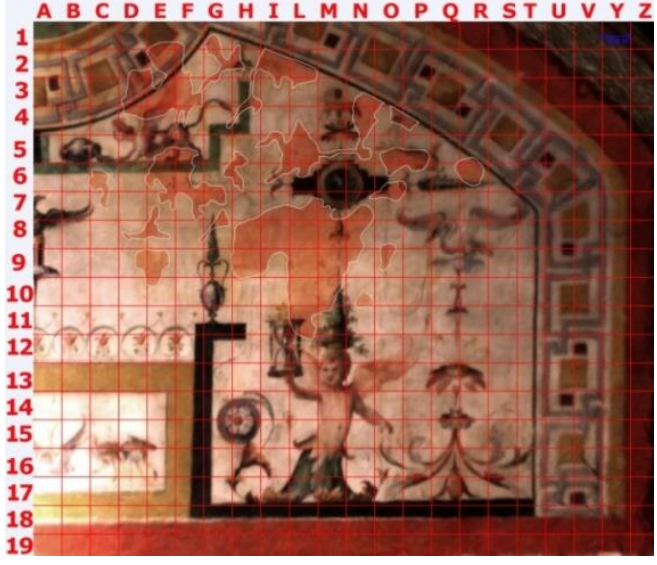

Figure 7. Photogrammetric details of the lunette at 1:1 scale.

the laser beam at a calibrated white target from several distances; the resulting curves were used during the post-process phase to normalise the colour channel values. The Landscape Room, which is about $10 \times 10 \times 3 \mathrm{~m}^{3}$, was digitalised in 4 days without needing to wait for optimal ambient light; the sun provided light during the day and artificial lights were used during the night.

\section{RESULTS}

The 3D scale model of the Stufetta tunnel vault obtained by photogrammetry makes it possible to focus on particular details in order to support and integrate the measurements and experimental results of other non-destructive testing techniques [24]. After the photogrammetric measurements were completed, the LIF scanning system was applied to the investigation of the Stufetta vault. In Figure 5, the false colour LIF image, reconstructed at 300, 400 and $500 \mathrm{~nm}$, is reported on the left. The relative photogrammetric image, with the measured area outlined by the yellow line, is reported as a reference on the right. As can be observed, some details not appreciable by the naked eye can be seen in the LIF image. In particular, the presence of a different material in the area of the angel's eyes is evident in the blue of the LIF false colour image. By analysing the LIF spectra resulting from these points, a narrow, intense emission band can be observed at $380 \mathrm{~nm}$ (Figure 6, lower spectrum). This band is ascribable to the presence of restoration materials probably containing zinc oxide, as suggested by the database developed in laboratory for cultural heritage materials in similar experimental conditions. Particular areas in the angel's chest also stand out in the fluorescence image; in this case, however, the relative spectra

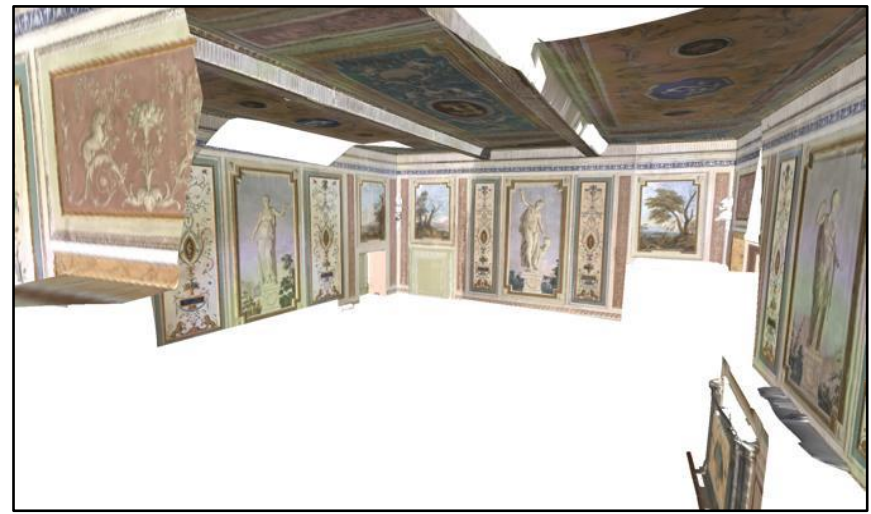

Figure 8. Partial 3D model reconstruction of the Landscape Room obtained by RGB-ITR scanner. 

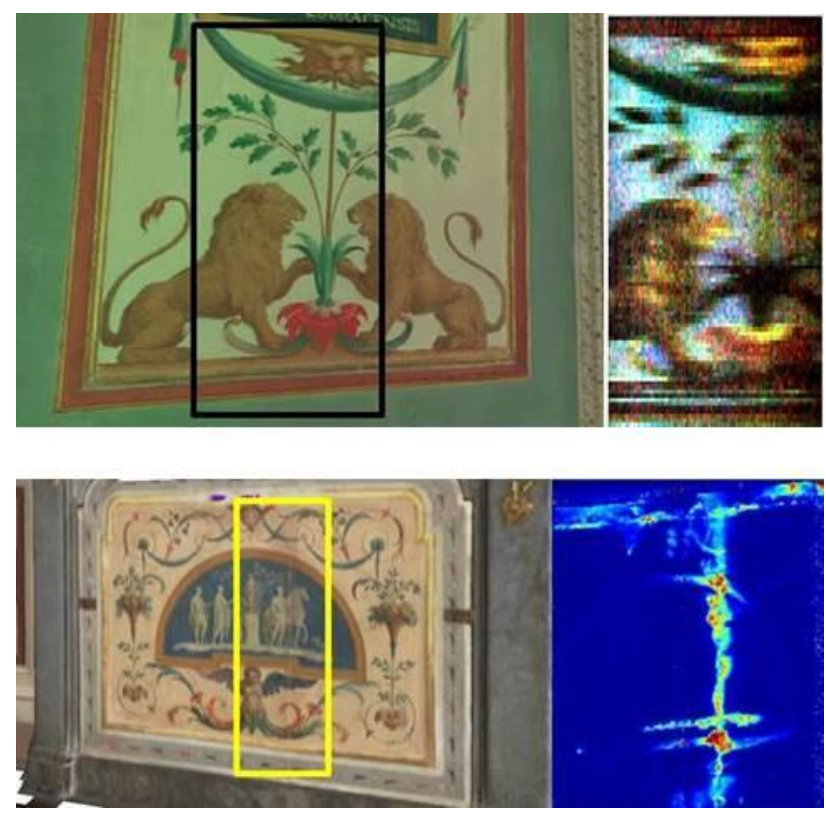

Figure 9. Top: RGB-ITR image with measured area in black line (left) and corresponding false colour LIF image (right).

Bottom: Fire screen RGB-ITR image, with measured area in yellow line (left) and corresponding LIF 380/450 $\mathrm{nm}$ image (right).

are the result of the superimposition of many different emission bands, implying the presence of a restoration material of different composition with a low concentration of zinc oxide.

A similar material was also found in other parts of the analysed surface. The presence of biodeterioration was also detected by the measurements. A grid of cell size equal to $0.05 \mathrm{~m}$ was defined in the lunette above the angel in the photogrammetric model in order to monitor the areas affected by humidity over time (Figure 7). LIF measurements make it possible to detect the presence of biodeterioration not only in those areas where it is visible by the naked eye but also in some areas where it is not visible at all. LIF spectra data of this kind of degradation is characterised by an emission band at $550 \mathrm{~nm}$

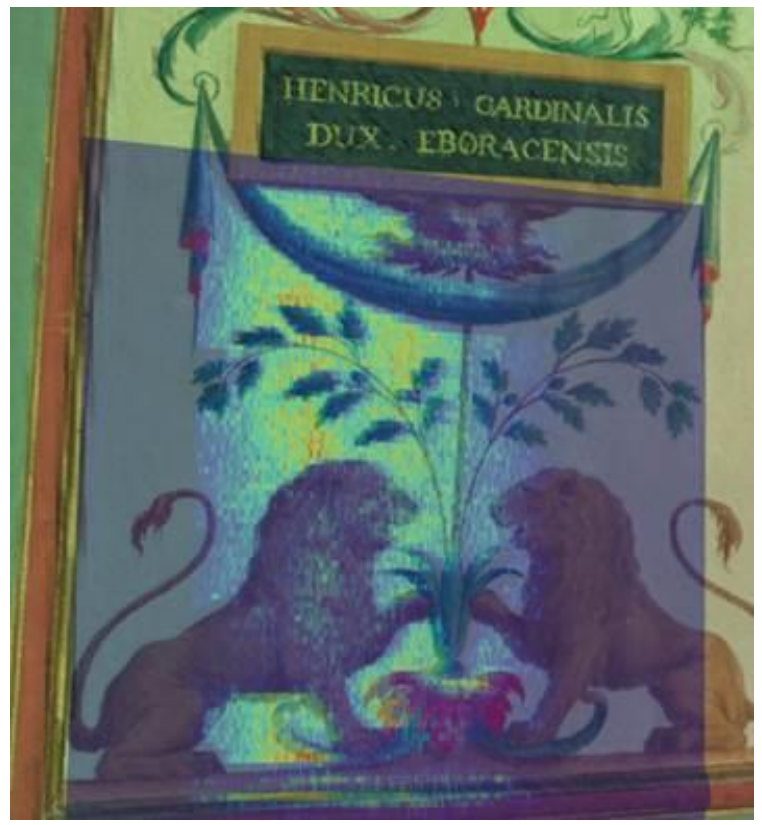

Figure 10. Superimposition of LIF image (in blue) onto the investigated area in the RGB-ITR model of the Landscape Room.
(Figure 6, upper spectrum) that is absent in the LIF spectra of non-deteriorated areas. This result, which makes it possible to discriminate between deteriorated and non-deteriorated areas even when the biodegradation is not visible, suggests the possibility of using LIF analysis for preventive monitoring to reduce the eventual induced damage.

The Landscape Room was also investigated. In the analysis of the Stufetta tunnel vault, the LIF maps were referenced to the 3D model, while the RGB-ITR laser scanner was used in the Landscape Room. A partial 3D model reconstruction of the room is reported in Figure 8. In this case, the LIF system did not detect any degradation or evidence of restoration on the painted walls, and the emission bands in all the collected spectra could be ascribed to cellulose, which reflects the textile substrate. In Figure 9 (top), the false colour LIF image of a detail on the painted left wall is shown next to the RGB-ITR image as an example. In contrast, the LIF results for the painted wooden fire screen in the room highlighted the discontinuity of the surface materials. In Figure 9 (bottom), the RGB-ITR image is shown on the left with the measurement area outlined, and the 380/450 nm fluorescence image of that area is reported on the right. As can be observed, added materials that are probably the result of restoration actions and/or degradation processes were once again localised by LIF analysis even though in some areas they are not visible by the naked eye.

The possibility of overlaying the LIF images onto the RGBITR 3D models in order to obtain some additional information was tested. To reference LIF data on a 3D point cloud, 4 or more pairs of common points are selected on the respective datasets, and standard algorithms are used to find the best affine transformation. Systematic error that arises during point positioning is attributed to the different resolutions between the two datasets: in this case, the RGB-ITR acquired the surface points with a spatial resolution of about $0.3 \mathrm{~mm}$, while the LIF data was obtained with a spatial resolution of $1 \mathrm{~mm}$. Automatic registration algorithms were not adopted because the correction of non-optical aberrations on the LIF dataset was introduced at this stage. In Figure 10, the superimposition of the false colour LIF image, in blue, onto the RGB-ITR image of the same analysed area of the Landscape Room is reported. No evidence of localised restoration materials or bio-degradation was revealed in this case, as affirmed previously.

Moreover, a post-processing analysis of the RGB-ITR 3D model was developed in order to identify areas of interest and evaluate eventual modifications based on images collected in previous periods [25]. The monitoring of the degradation processes could be provided in this way by repeating the measurements at different times.

\section{CONCLUSIONS}

The validity of the integrated approach developed in this work as a non-invasive diagnostic tool for cultural heritage has been demonstrated by the obtained results. Useful information can be obtained quickly by the synergistic application of the employed different techniques. The ability to localise areas in which biodeterioration processes are occurring or restoration materials have been applied in previous conservation actions has been verified, including for large surfaces. The collected data attested to the good quality, in some cases, of the restoration actions performed in previous years at the Bishop's Palace. The selected materials and techniques proved to be perfectly suitable for some retouches and integrations. However, degradation processes due 
to environmental humidity have been highlighted by the investigation. The possibility of preventive monitoring by the application of the presented approach to reduce eventual induced damage has been raised.

Work is in progress to optimise the process of integrating the data from the different techniques.

\section{ACKNOWLEDGEMENT}

This research was supported by the ADAMO project financed by Lazio Region for Technological Cultural District (DTC Lazio). The authors would like to thank the Episcopal Tuscolana Diocese for their support and hospitality and ENEA colleagues Marco Pistilli, Marcello Nuvoli and Massimiliano Ciaffi for fundamental logistical support.

\section{REFERENCES}

[1] J. P. Weibring, T. Johansson, H. Edner, S. Svanberg, B. Sundnér, V. Raimondi, G. Cecchi, L. Pantani, Fluorescence lidar imaging of historical monuments, Appl. Opt. 40(33) (2001), pp. 6111-6120. DOI: $\underline{10.1364 / A O .40 .006111}$

[2] D. Comelli, N. Björsell, A. Nevin, G. Valentini, I. Osticioli, E. M. Castellucci, L. Toniolo, D. Gulotta, R. Cubeddu, Insights into Masolino's wall paintings in Castiglione Olona: advanced reflectance and fluorescence imaging analysis, J. Cult. Herit. 12 (2011), pp. 11-18.

DOI: $10.1016 /$ i.culher.2010.06.003

[3] V. Raimondi, G. Cecchi, D. Lognoli, L. Palombi, R. Grönlund, A. Johansson, S. Svanberg, K. Barup, J. Hällström, The fluorescence lidar technique for the remote sensing of photoautotrophic biodeteriogens in the outdoor cultural heritage: a decade of in situ experiments, Int. Biodeterior. Biodegradation 63 (2009), pp. 823835.

DOI: $10.1016 /$ j.ibiod.2009.03.006

[4] L. Pantani, G. Ballerini, G. Cecchi, H. Edner, D. Lognoli, T. Johansson, V. Raimondi, S. Svanberg, P. Tiano, L. Tomaselli, P. Weibring, Experiments on stony monument monitoring by laserinduced fluorescence, J. Cult. Herit. 1 (2000), pp. S345-S348. DOI: $10.1016 /$ S1296-2074(00)00166-7

[5] D. Anglos, M. Solomidou, I. Zergioti, V. Zaffiropulos, T. G. Papazoglou, C. Fotakis, Laser-induced fluorescence in artwork diagnostics: an application in pigment analysis, Appl. Spectros. 50 (1996), pp. 1331-1334.

DOI: $10.1366 / 0003702963904863$

[6] G. Ricci, L. Caneve, D. Pedron, N. Holesch, E. Zendri, A multispectroscopic study for the characterization and definition of production techniques of German ceramic sherds, Microchemical Journal 126 (2016), pp. 104-112.

DOI: $10.1016 /$ j.microc.2015.12.009

[7] R. Grönlund, J. Hällström, A. Johansson, K. Barup, S. Svanberg, Remote multicolour excitation laser-induced fluorescence imaging, Laser Chem. (2006) art. 57934.

DOI: $10.1155 / 2006 / 57934$

[8] O. Abdel-Kareem, A. Eltokhy, M. A. Harith, Identification of natural dyes on archaeological textile objects using laser induced fluorescent technique, AIP Conference Proceedings 1380(1) (2011), pp. 70-76.

DOI: $\underline{10.1063 / 1.3631813}$

[9] L. Palombi, D. Alderighi, G. Cecchi, V. Raimondi, G. Toci, D. Lognoli, A fluorescence LIDAR sensor for hyper-spectral timeresolved remote sensing and mapping, Optics Express 21(2) (2013), pp. 14736-14746.

DOI: $\underline{10.1364 / O E .21 .014736}$

[10] J. Hällström, R. Grönlund, A. Johansson, S. Svanberg, L. Palombi, D. Lognoli, V. Raimondi, G. Cecchi, C. Conti, Documentation of soiled and biodeteriorated facades: A case study on the Coliseum, Roma, using hyperspectral imaging fluorescence lidars, J. Cult.
Herit. 10 (2009), pp.106-115.

DOI: $10.1016 /$ i.culher.2008.04.008

[11] M. J. Westoby, J. Brasington, N. F. Glasser, M. J. Hambrey, J. M. Reynolds, 'Structure-from-Motion' photogrammetry: a low-cost, effective tool for geoscience applications, Geomorphology 179 (2012), pp. 300-314.

DOI: $10.1016 /$ i.geomorph.2012.08.021

[12] R. Roncella, C. Re, G. Forlan, Performance evaluation of a structure and motion strategy in architecture and cultural heritage, International Archives of Photogrammetry, Remote Sensing and Spatial Information Sciences 38 (2011), pp. 285-289. DOI: 10.5194/isprsarchives-XXXVIII-5-W16-285-2011

[13] R. Fantoni, S. Almaviva, L. Caneve, M. Caponero, F. Colao, M. Ferri De Collibus, L. Fiorani, G. Fornetti, M. Francucci, M. Guarneri, V. Lazic, A. Palucci, V. Spizzichino, Laser scanners for remote diagnostic and virtual fruition of cultural heritage, Opt Quant. Electron. 49(120) (2017) 21 pages. DOI: $10.1007 / \mathrm{s} 11082-017-0952-4$

[14] M. Guarneri, M. Ferri de Collibus, G. Fornetti, M. Francucci, M. Nuvoli, R. Ricci, Remote colorimetric and structural diagnosis by RGB-ITR color laser scanner prototype, Adv. Optical Technol. 2012 (2012) art. 512902. DOI: $10.1155 / 2012 / 512902$

[15] A. Mihajlovski, D. Seyer, H. Benamara, F. Bousta, P. Di Martini, An overview of techniques for the characterization and quantification of microbial colonization on stone monuments, Ann. Microbiol. 65 (2015), pp. 1243-1255. DOI: $10.1007 / \mathrm{s} 13213-014-0956-2$

[16] K. Sterflinger, G. Piñar, Microbial deterioration of cultural heritage and works of art - tilting and windmills?, Applied Microbiology and Biotechnology 97(22) 2013 pp. 9637-9646. DOI: $10.1007 / \mathrm{s} 00253-013-5283-1$

[17] L. Caneve, F. Colao, R. Fantoni, L. Fiorani, Scanning lidar fluorosensor for remote diagnostic of surfaces, Nucl. Instr. Meth. Phys. Res. A 720 (2013), pp. 164-167. DOI: $10.1007 / \mathrm{s} 00253-013-5283-1$

[18] L. Caneve, F. Colao, L. Fiorani, R. Fantoni, L. Fornarini, Laser induced fluorescence analysis of acrylic resins used in conservation of cultural heritage, Proc. of the 2nd Int. Topical Meeting on Optical Sensing and Artificial Vision-OSAV'2008, St. Petersburg, Russia, 12-15 May 2008, pp. 57-63.

[19] H. M. Yilmaz, M. Yakar, S. A. Gulec, O. N. Dulgerler, Importance of digital close-range photogrammetry in documentation of cultural heritage, J. Cult. Herit. 8 (2007), pp. 428-433. DOI: $10.1016 /$ i.culher.2007.07.004

[20] J. McCarthy, Multi-image photogrammetry as a practical tool for cultural heritage survey and community engagement, J. Archaeol. Sci. 43 (2014), pp. 175-185. DOI: $10.1016 /$ i.jas. 2014.01 .010

[21] G. Ponti et al., The role of medium size facilities in the HPC ecosystem: the case of the new cresco4 cluster integrated in the ENEAGRID infrastructure, Proc. of International Conference on High Performance Computing and Simulation, HPCS 2014, Bologna, Italy, 21 - 25 July 2014, pp. 1030-1033. DOI: $10.1109 /$ HPCSim.2014.6903807

[22] R. Ricci, L. De Dominicis, M. Ferri De Collibus, G. Fornetti, M. Guarneri, M. Nuvoli, M. Francucci, RGB-ITR: an amplitudemodulated 3D colour laser scanner for cultural heritage applications, Proc. of International Conference on Laser in the Conservation of Artworks (LACONA VIII), Sibiu, Romania, 2125 September 2009.

[23] A. Danielis, M. Guarneri, M. Francucci, M. Ferri de Collibus, G. Fornetti, A. Mencattini, A quadratic model with non- polynomial terms for remote colorimetric calibration of 3D laser scanner data based on piecewise cubic hermite polynomials, Mathematical Problems in Engineering 2015 (2015) Art. 606948. DOI: $10.1155 / 2015 / 606948$

[24] M. Guarneri, S. Ceccarelli, M. Ferri De Collibus, M. Francucci1 M. Ciaffi, Multi-wavelengths 3D laser scanning for pigment and structural studies on the frescoed ceiling The Triumph of Divine 
Providence, The International Archives of the Photogrammetry, Remote Sensing and Spatial Information Sciences XLII-2/W15 (2019), pp. 549-554.

DOI: 10.5194 /isprs-archives-XLII-2-W15-549-2019

[25] M. Mongelli, I. Bellagamba, A. Perozziello, S. Pierattini, S Migliori, A. Quintiliani, G. Bracco, A. Tatì, P. Calicchia, Photogrammetric survey to support non destructive tests at St. Alexander Catacombs in Rome, Proc. of MetroArcheo2018,
Cassino, Italy, 22 - 24 October 2018, pp. 308-313.

DOI: $\underline{10.1109 / \text { MetroArchaeo43810.2018.13634 }}$

[26] L. Caneve, M. Guarneri, A. Lai, V. Spizzichino, S. Ceccarelli, B. Mazzei, Non-destructive laser based techniques for biodegradation analysis in cultural heritage, NDT\&E International 104 (2019), pp. 108-113.

DOI: $\underline{10.1016 / \text { i.ndteint.2019.03.007 }}$ 